\title{
Faith Development While Abroad Amongst African American Students
}

\section{Thandiwe Dinani}

Belmont University

\begin{abstract}
:
Spiritual development is an epistemological journey of seeking to make meaning of life's activities, order, and relationship between events (Love, 2002). This process occurs when students experience a degree of dissonance that pushes them to question what they know, how they know it, and expand their understanding based on new experiences and information learned (Bakari, 2000; Chaudhari \& Pizzolato, 2008). Studying abroad provides opportunities for students to encounter disequilibrium as they interact with other cultures that cause them to consider alternative viewpoints, and enable other's practices and beliefs to influence the formation of their own views, beliefs and practices (Chaudhari \& Pizzolato, 2008). This article utilizes Fowler's (1981) stages of faith development to understand the meaning-making and spiritual development of study abroad participants. Multiple semi-structured interviews (pre-, during, and post-study abroad) were conducted with 25 AfricanAmerican students who participated in long-term, immersive, study-abroad programs in thirteen different countries on five different continents. Results show transitions, changes, and development of students' faith while abroad.
\end{abstract}

\section{Introduction}

Study abroad programs provide the opportunity for self-exploration and personal development. Programs can enhance both cognitive and affective skills, and increase cultural empathy and intercultural awareness (Braskamp, Braskamp \& Merrill, 2011; Carlson \& Widaman, 1988; Kauffman \& Kuh, 1984; Mahon, 2009). While abroad, students engage with new personalities and social norms as they experience a lack of power in unfamiliar surroundings. Navigating different cultural dynamics and systems challenge students to alter their approaches to forming relationships as they learn what is considered culturally appropriate and inappropriate behavior in their new environment (Carlson \& Widaman, 1988; Kauffman \& Kuh, 1984; Younes \& Asay, 2003). When confronted with varying values in their host cultures, students are challenged to self-examine their own behaviors and values. These challenges allow students the opportunity to recognize and reflect on how their behaviors affect others, acquiring a degree of multicultural training (Jenkins, 2011; Jewett, 2010; Kauffman, Martin, \& Weaver, 1992; Younes \& Asay, 2003). As students learn how to value, respect, and appropriately engage with others, they develop a more comprehensive and complex view of the world (Chickering \& Braskamp, 2009; Johns \& Thompson, 2010; Kauffman \& Kuh, 1984; Morgan \& Toms-Smedley, 2010; Younes \& Asay, 2003).

Studying abroad provides opportunities for students to encounter disequilibrium as they interact with other cultures that cause them to consider alternative viewpoints, and enable other practices and beliefs to influence the formation of their own views, beliefs, and practices (Chaudhari 
\& Pizzolato, 2008). This disequilibrium is essential in order for students to recognize that there may be answers beyond their immediate understanding, creating further development of identity, faith, and more. Students arrive at college with an understanding of themselves and others. During their first year, their understanding of self and others is continually challenged, and students develop greater understanding with each encounter, classroom learning, and interaction. Throughout their collegiate years, they may return time and again to the same conversations; with each reoccurrence, they build on former knowledge and develop greater understanding of self and others.

In order for further development to occur, students need to experience a degree of dissonance that pushes them to rethink the way they view things. Similarly, students need to continually question their beliefs about themselves, and the information they learn (Pizzolato et al., 2009). Chaudhari and Pizzolato (2008) propose that epistemological development is enhanced by attempts to make meaning of situations wherein the right answer is unclear; when presented with new information, people are challenged to reconsider their ways of knowing and being. Experiences that create disequilibrium are opportune moments to question and explore self-understanding. These experiences occur frequently amongst college students. Epistemological development entails moving from relying on external factors to developing a strong internal sense of self, using internal strength to understand knowledge (Chauhari \& Pizzolatio, 2008; Pizzolato et al., 2009).

\section{Epistemological Development}

William Perry (1970) provided seminal research on epistemological development, explaining that college students make meaning of their educational experiences through a cyclical process and sequence. Perry describes four stages of meaning-making: duality, multiplicity, relativism, and commitment-within-relativism (Evans, Forney \& Guido-DiBrito, 1998; Perry, 1970; Thomas, 2003). In the Duality stage, knowledge is received and highly regarded from authority, and there is a belief in absolute truths. In addition, one's epistemology (meaning-making) in this stage is clearly unified, but there is a simplistic, mechanical and literal interpretation of complex situations (Thomas, 2003). This could appear in religious, political, economic and/or racial perspectives of other groups, or of one's own. When asked how they know their thoughts are true, typical answers would be "I just know," "that's what everyone says," "everything you read/see says so."

Perry's second stage, multiplicity, refers to acknowledging the role that ambiguity plays in in truth-making and truth-telling (Thomas, 2003). In this stage, there is a tendency to favor a subjective view of situations while struggling with logical alternatives. When faced with facts that could alter opinions and world-views, students struggle with how this new information challenges their previously-learned views, and may retreat to their familiar and comfortable view points. In this stage, pluralism thrives - since there is no ultimate truth, all views must be of equal worth (Thomas, 2003). Statements indicative of this stage, would be similar to "people here are so different than back at home," or "I don't even know what to do after all this new information."

In the relativism stage, there is acknowledgment and understanding that there is ambiguity in life, and knowledge and truth is formed in complex contexts based on evidence and supporting arguments (Thomas, 2003). Truth can therefore exist in multiple contexts, and conflicting truth can be argued from multiple perspectives. This would be seen in statements, such as "That is your 
truth," "your world, your truth," and common phrases heard amongst current college students are "I do me, you do you," and "you can't judge me or my truth".

Lastly, the stage of commitment-within-relativism recognizes that knowledge is complex and not delivered in concise packages and presentations, however it is still amenable to analysis, evaluation, reflection and eventually commitment (Thomas, 2003). Statements in this stage may be "I've considered various points of view, and here's what I believe to be true," or "each person provides a unique and valuable perspective, I have some additional thoughts to further the conversation." A dualistic epistemology and commitment-within-relativism epistemology may appear similar because both view truth as something that can be known and evaluated. However, a dualistic epistemology holds a very shallow view, whereas commitment-within-relativism epistemology wrestles with the complexities and uncertainties of life before coming to a conclusion that some things are true, valuable, and worthy of commitment (Thomas, 2003).

Chaudhari and Pizzolato (2008) provide additional perspective of the epistemological development of college students. They posit that a students' epistemic knowledge formation occurs in three dimensions: cognitive, interpersonal, and intrapersonal. Cognitive dimensions entail students developing their ability to understand knowledge as concrete, and understand that knowledge is contextual (Chaudhari \& Pizzolato, 2008; Pizzolato et al., 2008; Sisneros, Stakeman, Joyner, \& Schmitz, 2008). When students enter college, they see their professors as the authorities on information presented; through experiences, they learn to question authority and balance information against their own thinking (Pizzolato et al., 2008). Furthermore, Chaudhari and Pizzolato (2008) explain that interpersonal dimensions are assumptions that are made based on relationships with others; students attempt to define their identity based on interactions with others similar and different than themselves. Students begin this dimension by being unsure about how to understand and manage relationships; they complete this dimension by setting boundaries and expectations for relationships (Chaudhari \& Pizzolato, 2008). They develop their own goals, values and beliefs about how they choose to interact with others (Pizzolato et at, 2008). Lastly, intrapersonal dimensions are assumptions focused on understanding and sustaining personal being and identity. Students are concerned with questions such as, "Who am I?" (Chaudhari \& Pizzolato, 2008).

\section{Identity Development}

One's identity is comprised of multiple components, some of those aspects being: racial/ethnic identity, socioeconomic status, political ideology, gender, sexual orientation, religious identity. In each component of one's identity, the same epistemological questions are raised, explored, and answered. Chickering and Reisser (1993) compare identity development to assembling a jigsaw puzzle: connecting competence, emotional maturity, autonomy, and positive relationships. However, I would argue identity development is more comparable to a scavenger hunt than assembling a jigsaw puzzle because the stages of development build upon each other. As individuals understand their own identity, they are able to understand their autonomy and interdependent relationships within the larger community. As one has encounters and experiences, a person determines what they believe, and how they will operate based on those beliefs. 
Identity development theories commonly find their foundations in one of two theoretical frameworks: psychosocial or cognitive (Chickering \& Reisser, 1993). Psychosocial theories view development as series of stages — one progresses in thinking, feeling, behaving, valuing, and relating to others and self (e.g. Erikson's eight developmental stages, Chickering's seven vectors of development, Cross's model of black identity formation). Cognitive theories view development as changes in thinking and expanded schemas of values, beliefs, and assumptions (e.g. Kohlberg's theory of moral development, Perry's scheme of intellectual and ethical development, Baxter Magolda's epistemological reflection model, Kitchener and King's reflective judgment model).

Psychosocial theories of identity development find their foundation in Erickson's psychosocial stages of development (Chickering \& Reisser, 1993; Cross \& Fhagen-Smith, 2001; Morse, 2002; Williams, 2006). Erikson saw social contexts affecting developmental stages; when confronted with challenges, individuals either progress, regress, stand still, or have recurring bouts with the same issue (Chickering \& Reisser, 1993; Erikson, 1968; Williams, 2006).

During adolescence an individual encounters the identity vs. role confusion stage. This stage is predominantly consumed with developing a social identity, a sense of self and personal identity. It is at this stage of development that a person has the physiological growth, mental maturation, and social responsibility to navigate challenges and crises of identity (Astalis, 2005; Erikson, 1968). If this stage is navigated successfully, an individual emerges with an ability to stay true to themselves; if not, they emerge with a sense of role confusion and a weak sense of self (Astalis, 2005; Erikson, 1968; Waterman, 1999).

\section{Religious Identity, Spiritual and Faith Development}

A person's spiritual development can be considered an epistemological journey of seeking to make meaning of life's activities, order, and relationship between events (Love, 2002). In alignment with information already covered, Fowler (1981) explains that a person's faith is the way he or she sees themselves in relation to others in the context of a shared meaning and purpose. He further explains that prior to a person becoming religious or irreligious, before one chooses to identify as Catholic, Protestant, Jew, or Muslim, he or she is concerned with how to compose their life and how to make a life worth living (Fowler, 1981).

It is important to understand the difference between faith, religion, and belief. Fowler (1981) explains that faith is a person's or group's way of responding to divine value and power through forms of cumulative tradition, whereas belief is a way that one expresses faith. Faith and religion are reciprocal and cyclical processes - faith is invigorated and renewed by aspects of the tradition (religion). In turn, these aspects of faith when expressed by new adherents extend and modify the tradition (Fowler, 1981). To further clarify the distinction between faith and belief - a person does not have faith in a concept, a person believes a concept. A person's faith is the degree of trust he or she has in the divine about a concept (Fowler, 1981). An example would be, a person may hold a belief that there is life after death; the degree to which a person believes this to be true is their amount of faith in a God that will grant them life after death. Faith involves an alignment of the heart or commitment to trust, and loyalty to a concept. It is a way of knowing, and a way of living life being shaped by that commitment. In contrast, belief is the holding of certain thoughts and ideas in an effort to make meaning of experiences into concepts or stances. 
Fowler also created stages to explain the development of faith. Fowler's (1981) first stage of faith development is called intuitive-projective faith. This fantasy-filled stage is typically seen in children who can be powerfully and permanently influenced by examples and stories told by adult relatives. A child's imagination forms long-lasting images and feelings that become more grounded as they reflect and mature. Similarly to Perry's first stage of epistemological development, Fowler's intuitive-projective stage of faith development is highly influenced by authority figures who hold and regulate all knowledge.

Fowler's next stage of faith development, mythic-literal, is typically seen in the upper elementary school grades, however some adolescents and a few adults also exhibit these characteristics. In this stage, people begin to coordinate their own perspective with others, and begin to own the beliefs and observances that symbolize belonging to the community of believers. In addition, in this stage, symbols have literal meaning rather than symbolic meanings and beliefs are also literal (Fowler, 1981).

People transition to Fowler's third stage, synthetic-conventional faith, when they encounter a clash or contradiction in stories that lead to an evaluation of meanings (Fowler, 1981). In this stage, the person relies on the sound advice of a few trusted people with whom they feel secure enough to share their newly formed feelings, insights, anxieties and commitments. Authority still resides outside of one's self, typically in institutional leadership roles. A person in this stage is able to articulate their values and normative images, feels a deep emotional investment in these values, and is willing to defend the group's value system. However, they are not able to recognize that the value system taught by the group is in-and-of-itself a system that is designed to form similar thinking and behaviors amongst group members (Fowler, 1981). A person's world extends beyond the family, and consists of extended family, school or work, peers, society, media, and perhaps religion. Therefore, their faith provides a coherent orientation to counter the complex and diverse range of involvements. However, any strategy to demythologize symbols or sacred elements of their faith is seen as a threat to the symbol and symbolized, and is considered an assault on the sacred (Fowler, 1981). This stage is characterized by a conformist tendency, because people are very aware of the expectations and judgments of significant others, do not have a secure grasp of their own identity, and lack autonomous judgment to construct an independent perspective (Fowler, 1981).

Characteristics of this stage are observed quite often amongst first-year college students who were raised in strong faith communities. During their high school years, these students typically have routines wherein norms and expectations are regularly reinforced (e.g., bi-weekly church services, parental influences, regular interaction with peers from the faith community). Any person who questions their thinking is considered to be an outsider, enemy, or they may be shown a degree of sympathy because, the assumption is, that the person is lost or misinformed. In order to avoid being categorized as an outsider, enemy, lost, or misinformed, people within the group work hard to show they are indeed part of the group. In many instances, they are not aware that they are conforming to group-think - when one hears coherent information numerous times, they not only believe the information, they can reiterate the information verbatim. Consequently, anyone who challenges the information is seen as challenging more than the information, they appear to be challenging the entire system. 
When students, who have been raised in strong faith communities where their good conformist behavior was applauded by parents and their faith communities, leave their prescribed communities for college, many unknowingly expect similar environments when they arrive at college, and therefore operate in the same manner as they did in their faith community. When they encounter others who are modeling an alternate faith community's value system, they begin to realize just how differently faith communities communicate expectations of how their value systems should be modeled. Initially, they may assume that someone who does not share their same value systems is not a person of faith. They soon begin to question, and eventually embrace others who believe similarly and differently than them.

When people encounter and respond to situations that lead to critical reflection on their value systems (e.g., clashes or contradictions between valued authority sources, marked changes by officially sanctioned leaders), they begin to transition to stage four: individuative-reflective faith (Fowler, 1981). Whether one will transition to individuative-reflective stance depends on the character and quality of the competing ideologies of both groups. For a genuine transition to occur there must be an interruption of reliance on external sources of authority and the emergence of an independent personality (Fowler, 1981).

Fowler (1981) identifies the college environment, travel, or moving from one community to another as natural transition periods that provide students opportunities to interrupt reliance on external authorities, because they are required to reflect on their own value systems when confronted with other perspectives. However, many fail to interrupt their reliance on external authorities (and sometimes reinforce their reliance) in order to cope with the newly encountered relativity (Fowler, 1981). Similarly, studying abroad also provides the opportunity for students to interrupt their reliance on external authorities as they experience physical distance from their authority figures.

\section{Faith Development while Abroad}

A research study was conducted on the undergraduate experience of twenty five AfricanAmerican students, participating in immersive study abroad programs in thirteen countries on five continents. All students attended public, land-grant research institutions in the Mid-West. Prior to leaving for their study abroad programs, three participants mentioned that they were Christian, but they did not talk about any intentions to connect with a church or group of believers while abroad. While abroad, one-third of the participants searched for churches in their host countries and regularly attended services during their study abroad program. In addition, while overseas and upon return, additional participants mentioned having some type of involvement with churches in their host countries. Upon return to the U.S., the majority of these students discussed how their involvement in churches in their host country had a significant impact on their faith. In the following student reflections, names have been changed to protect anonymity.

\section{Finding a Faith Community While Abroad}

Dana was a student who identified as a person of faith during her initial interview prior to studying abroad. When asked about her thoughts of studying abroad as an African-American female, she commented, "I think it will be fine. In the beginning, I was a little nervous because it's new, but I know that God's going to protect me. I'm going to be fine." She did not discuss her faith any further, and did not allude any further that she was religious in any capacity. I did not push the 
topic further since it seemed to be an off-the-cuff comment to provide a nice response to finish a statement. Dana did not make any additional comments about God or faith throughout the remainder of the conversation.

During her first month abroad, Dana and I talked about her initial experiences. She shared that she had found a few students with a similar faith background, and invited them to accompany her to the church she found. Throughout her five months abroad, Dana did not share further about attending church, but she did make statements that revealed she had a faith background (e.g., praying for strength, God protecting her, finding strength and peace in a place where it is easy to forget who you are). It was only during her last interview while abroad that Dana shared that she had been attending church the entire time she was abroad:

The first week that I was here, I looked into the yellow pages and emailed the pastor and said I was new in [host country] but didn't want to trek there myself, and no one here wanted to go, so he volunteered to pick me up. It was definitely a leap of faith because I was like "I do not know these people at all." But it was a great service and they definitely have a great community there. And they expressed "Whatever you need, just let us know. Just call us, we want to be here for you." So that was very comforting from the beginning just to have a community there, not only of faith but of people who will look out for you and check up on you every now and then.

Dana explained why she chose to find a church to attend in her host country:

I think that I knew myself in terms of what I would need in a new environment. I knew that people were going to be huge for me, obviously safety, but the people can either make your experience good or bad. I know back home my faith community has been very instrumental in just helping me with school and things like that, so I knew that for me I needed that. So that definitely helped me adjust because if not, I would have probably been like, "Oh I want to go home."

In reflecting on Dana's words, she shows the importance a faith community has to her emotional and mental state. She relied on the community to provide strength when she was lonely and uncertain. Dana's decision to ride in a car with complete strangers reveals the level of trust she has for authority figures in a faith community - she trusted them to protect her and did not question whether they had any ill intention.

Tanya was also open about her faith prior to leaving the United States; she shared that she planned to get involved with Christians in her host country. On her home campus, she was "really involved with a Christian ministry, and I didn't realize there's the same ministry there, so... I'm taking another part of my identity-my Christianity." Tanya revealed aspects of her faith development, her beliefs about others, and how she planned to interact with others who did not share her beliefs:

Another thing I've been thinking about is the religious atmosphere in [host country]. From what I've seen and heard it's predominantly agnostic, like non-practicing Catholic, and then the rest is like agnostic/atheistic. So as a Christian trying to work in a ministry that focuses on sharing the gospel, I might have a hard time, a language barrier. But I feel there's a reason I'm going to [host country] and I just really want my skills to be able to help me talk to 
people and form good relationships with people, so I don't lose my identity, and I can also share my identity with other people... People told me it's a spiritually dark place. They're kind of hollow. Like it looks pretty, but there's not much there. I have a lot to think about, but I think I'm ready.

From Tanya's words, you can see her stage of faith development is in syntheticconventional stage. Her use of words such as "dark" and "hollow" reveals a level of judgment of others who do not understand what she has come to understand. She believes an aspect of her purpose in going to her host country is to convert people to Christianity. In sharing her faith with others, she will also reiterate her own beliefs and identity.

\section{Deepening of Faith While Abroad}

Participants also discussed how their faith had deepened while abroad. Participants shared some of the lessons learned in their host counties and how those lessons impacted their faith. Dana shared during her last interview abroad about how being independent caused her to rely on God since she did not have her normal support systems:

This whole process and just being on my own has increased my faith in God, because I cannot control half the things that do happen and will happen... increasing my faith and really trusting that everything is going to work out over here. I can't just call home and tell mom or dad about it, and ask for help. I'm doing everything on my own.

Similarly, Tina shared about her faith changing as a result of no longer having her safe "bubble." She interacted with new people and heard differing perspectives:

There were things I never really thought about-wisdom being learned. But a lot of things, it's been "Oh, that's what that means." When I was in the U.S., I had my comfort zone and felt comfortable talking about my faith. But I guess going to a different place, I realized I closed myself in. I am getting out of the Christian bubble. We had a retreat this past weekend, really challenging me to go out and be bold in my faith.

During her last interview while she was abroad, Patricia also shared how much her faith had been impacted by encountering new people, concepts, and being independent:

Faith-wise, this trip has been a spiritual journey. Mostly, because God wants me here, there's a reason why I'm here with this group of people. I feel like I'm a lot better about going to church here than I was back on campus. Last year, I didn't go to church almost at all because of classes. And here it's like, “Oh my gosh if I don't go, I'm going to miss out on seeing people and my friends, and I'm going to miss out on what we're learning here." I feel like everything we've talked about at church applies to me, like trusting in Him, learning how to let go of things, focusing on the important things. Starting with prioritizing God, everything falls into place. Being open about speaking about your faith. People ask questions all the time, and I'm supposed to be saying what I've learned. Being able to give more, instead of everyone enriching your experience.

In all three stories, you can see the unique opportunity study abroad provides students. In leaving the familiarity of home, students have to rely on themselves for their day-to-day needs. This independence causes them to realize they have internal strength that is separate from their social 
groups and faith groups. During their interactions with faith communities, they learn new concepts about what they are supposed to be doing and thinking. Interestingly, you can see the conformity stage still emerging in their comments. They trust and follow the lessons taught by the spiritual figures in their host countries similarly to how they would trust and follow their spiritual leaders back at home.

\section{Evaluating Faith Upon Returning Home}

Prior to studying abroad and while abroad, participants reveal a synthetic-conventional stage of faith development. However, their interactions with faith communities and the time away from their homes impacted them more than they anticipated. Upon return to their homes and home faith communities, participants began to see the differences in faith communities and their personal faith development. Upon return to the U.S., Dana was able to articulate differences between her faith communities abroad and at home:

I think that in the United States, we see the gospel as very self-centered — God help me. We see blessings as a car or like a job, just having a very microscopic view of who God is, and more of a religious thing-like "I'm going to be religious" or "I'm going to be a good person." I learned over there about knowing all of who God is and that bad things happen, not because he's punishing us. And I learned more about God, and just like there's also a lot of fluffy things that happen in church, too, that are not necessary, and can take away from the core of why you go.

Tina also shared the differences she noticed between churches in the States and abroad:

It's interesting because even throughout college when I started to take my faith more seriously, I was in church communities that were more [focused] towards a contemporary, almost White Christian. So it was a lot more of like calmer worship. I guess introspective is the best way to put it. My church in Southern Europe was more international, but it's still pretty contemporary. Like, we don't really sing gospel songs or stuff like that. Also, our church in Southern Europe was more situated for a young 20s or 30s that are traveling for a while... so a lot of the sermons focus a lot on making time for God, things to center young people and stuff. I haven't been to my church back home for a while, but I know more of Black worship can be on God's power and his ability to do things. Not to say that either of those are wrong. Those are all aspects of him.

Patricia made an interesting observation, she noticed the messages were the same, but her ability to hear them was different in the U.S. than abroad. When asked if there was a difference in what her church emphasized at home than what her host country church emphasized, Patricia shared, "I think they're saying the same things like home, but here everything is amplified, and I'm seeing weaknesses in my faith. Coming here, I'm like 'Oh, that's what I'm supposed to be doing.' I'm hyper aware of things because I'm not at the same church.”

This last set of comments show the beginning of a transition from synthetic-conventional to individuative-reflective. After being abroad and experiencing new forms of worship, variance in messages, conversations with fellow believers, participants were able to see differences in faith communities and to evaluate how both communities view God, the role of faith, and the responsibilities of believers who choose to be part of the community. A follow-up question asked 
to those who identified differences in the faith communities was, what will they do with their newfound knowledge?

Dana acknowledged that the noticeable difference in her home church and the church she attended while abroad had led to growth pains: "I learned a lot spiritually and it has shaped what I look for when I'm looking for a church right now. I grew up in a church home here, but I'm kind of...having growth pains." Tina also discussed the adjustment back to America:

I've been thinking about this a lot. I've just been seeing the importance of finding-and to me it's not just religion - the importance of finding a good community of believers that's available. It's a lot easier to find here in America than it is in Southern Europe, which is overall, pretty atheist or agnostic. So my church that I was in growing up, I didn't really have that good of a relationship with them. So I don't even know if I'll go back to that church... Of course, there's no way I can mimic the same type of community, but just seeking out a community that I can pour into and that can pour into me as well.

These statements and questions are common amongst college-aged students whether they study abroad or remain at home. With new knowledge and experiences gained, students question how they will return to their faith communities in the same manner and expectations as they left for college. With these participants, they were nearing the end of their college experiences and had not transitioned in to the next stage of faith development. Studying abroad and encountering a community of believers in another country prompted the questions and further development of faith.

\section{Conclusion}

Study abroad provides students with unique opportunities to engage with different cultures, gain independence, and develop cultural empathy and sensitivity. Furthermore, it can impact aspects of a person's identity far beyond expectation. For the students studied, their host universities and program providers did not discuss their religious identity, needs or support with them. Yet, it was a very important aspect for these students. Their faith communities had the most profound impact on their identity beyond any other aspect of the programming implemented at their institutions and by providers.

Continued efforts need to be made to understand the student experience and provide adequate support while abroad. Establishing rapport, learning student's backgrounds, and identifying areas of growth for each student is essential. Study abroad offices and overseas partners need to collaborate on identifying areas of growth for each student, recognizing that unexpected areas of a student's identity may provide the greatest areas of growth. In addition, reflective questioning throughout the entirety of a study abroad experience empowers students to take time to consider the implications of their experiences, and to determine how they want to incorporate lessons learned into their lives upon return to the U.S.

Further research needs to be conducted to determine whether there are similarities and differences in the faith development of students from various religions. Fowler's work focused on people of Christian faith, however his explanations would seem applicable to more than Christian students. In addition, this study was conducted amongst African American students. It would be 
interesting to see if there are similarities or differences amongst students of other races. Fowler's work was conducted primarily with white students, so it would be assumed research conducted with students of other races would have similar results.

\section{References}

Astalis, P. A. (2005). Locating identity: The influence of Erik H. Erikson on society andthe social construct of adolescence (Doctoral dissertation). Alliant International University. Retrieved from ProQuest Dissertations and Theses. (AAT 3170769)

Braskamp, L. A., Braskamp, D. C., \& Merrill, K. C. (2011). Assessing progress in global learning and development of students with education abroad experiences. Frontiers: The Interdisciplinary Journal of Study Abroad, 18(Fall), 101-118.

Carlson, J. S., \& Widaman, K. F. (1988). The effects of study abroad during college on attitudes toward other cultures. International Journal of Intercultural Relations, 12(1), 1-17. doi:10.1016/01471767(88)90003-X.

Chaudhari, P., \& Pizzolato, J. E. (2008). Understanding the epistemology of ethnic identity development in multiethnic college students. Journal of College Student Development, 49(5), 443-458.

Chickering, A., \& Braskamp, L. A. (2009). Developing a global perspective for personal and social responsibility. AAC \& U Peer Review, 11(4), 27-30.

Chickering, A. W., \& Reisser, L. (1993). Education and identity (2nd ed.). San Francisco, CA: JosseyBass.

Cross, W. E., \& Fhagen-Smith, P. (2001). Patterns of African American identity development: A life span perspective. In C. L. Wijeyesinghe, B. W. Jackson III. (Eds.), New perspectives on racial identity. (pp. 243-268). New York: New York University Press.

Erikson, E. (1968). Identity: Youth and crisis. New York, NY: W. W. Norton \& Company.

Evans, N. J., Forney, D. S., \& Guido-DiBrito, F. (1998). Student development in college: Theory research, and practice. San Francisco, CA: Jossey-Bass.

Fowler, J. W. (1981). Stages of faith: The psychology of human development and the quest for meaning. San Francisco: Harper \& Row.

Jenkins, K. (2011). International education today to prepare the leaders of tomorrow. Diverse Issues in Higher Education, 28(5), 17.

Jewett, S. (2010). "We're sort of imposters": Negotiating identity at home and abroad. Curriculum Inquiry, 40(5), 635-656. doi:10.1111/j.1467-873X.2010.00515.x

Johns, A., \& Thompson, C. W. (2010). Developing cultural sensitivity through study abroad. Home Health Care Management \& Practice, 22(5), 344-348. doi:10.1177/1084822309353153

Kauffmann, N. L., \& Kuh, G. D. (1984, April). The impact of study abroad on personal development of college students. Paper presented at the Annual Meeting of the American Educational Research Association, New Orleans, LA.

Kauffmann, N. L., Martin, J. N., \& Weaver, H. D. (1992) Students abroad: Strangers at home Education for a global society. Yarmouth, ME: Intercultural Press.

Love, P. G. (2002). Comparing spiritual development and cognitive development. Journal of College Student Development, 43(3), 357-373.

Mahon, J. (2009). Authority and imposition in the study abroad curriculum: A poststructural lens. Journal of Curriculum Theorizing, 25(3), 68-83.

Morse, R. E. (2002). Black racial identity development and epistemological development in college (Doctoral dissertation). Retrieved from ProQuest Dissertations and Theses. (AAT 3057468)

Morgan, R. J., \& Toms-Smedley, C. (Eds.). (2010). Transformations at the edge of the world. Abilene, TX: Abilene Christian University Press.

Perry, W. G., Jr. (1970). Forms of intellectual ethical and intellectual development in the college years. New York, NY: Holt, Rinehart \& Winston. 
Pizzolato, J. E., Chaudhari, P., Murrell, E. D., Podobnik, S., \& Schaeffer, Z. (2008). Ethnic identity, epistemological development, and academic achievement in underrepresented students. Journal of College Student Development, 49(4), 301- 318.

Pizzolato, J. E., Hicklen, S. T., Brown, E. L., \& Chaudhari, P. (2009). Student development, student learning: Examining the relation between epistemologic development and learning. Journal of College Student Development, 50(5), 475-490.

Sisneros, J., Stakeman, C., Joyner, M. C., \& Schmitz, C.L. (2008). Self-awareness, critical reflectivity, and identity. In Critical multicultural social work (pp. 20-37). Chicago, IL: Lyceum Books.

Thomas, M. (2003). Shifting epistemology: Tracing the history behind the nature of knowledge in American higher education, forming the foundations of student intellectual development theory. American Educational History Journal, 30(1), 23-30.

Waterman, A. S. (1999). Identity, the identity statuses, and identity status development: a contemporary statement. Developmental Review, 19(4), 591-621. doi:10.1006/drev.1999.0493

Williams, B. M. (2006). Expanding perceptions of self and other through study abroad (Doctoral dissertation; The Ohio State University). Retrieved from ProQuest Dissertations and Theses.

Younes, M. N., \& Asay, S. M. (2003). The world as a classroom: The impact of international study experiences on college students. College Teaching, 51(4), 141-147. 